\title{
What does it mean to be a teacher? Three tensions within contemporary teacher professionalism examined in terms of Government policy and the knowledge economy.
}

\author{
Sandra Leaton Gray \\ Cambridge University
}

Published in FORUM (48) 3 (2006):305-315

\begin{abstract}
This article debates three tensions within the contemporary teaching profession in Great Britain, in terms of education policy after the 1988 Education Reform Act. The first is between prospective and retrospective identities, as defined by Bernstein (2000). The second is between teachers' expectations of professional status, and centralised and highly regulated school inspections. Finally, the article looks at vocation in the teaching profession, and how this comes into conflict with issues of self-interest amongst teachers. The article concludes by suggesting another tension that is evident throughout all three earlier strands of debate, between democratic professionalism (Whitty, 2002) and the post-1988 education landscape. The article closes by suggesting that a future education act in favour of a more humane education system may resolve this situation.
\end{abstract}

\section{Introduction}

I have been using drawings and objects to stimulate debate about models of teacher professionalism amongst education students for some years now. One of the more intriguing highlights of my collection of educational artefacts is "Teacher Barbie". She is everything popular culture might desire from a gender stereotype. The doll has a kind, smiling face, and is dressed in a fetching pinafore which has rulers, apples and digits printed all over it in bright colours. She comes with the usual teacher doll accessories. Barbie has her own chalk board with sound effects (school bell, musical scale, children laughing), and three lesson charts dinosaurs, a musical score, and a world map.

The stark reality of the classroom today is somewhat different, of course. Fortunately, Teacher Barbie in no way represents the contemporary teaching profession. Nevertheless there are problems with perceptions of education and the status of teachers within modern society. One reason for this could be that there seem to be many confusions and disagreements in locating teacher identity within the post-industrial knowledge economy. This article therefore explores three tensions embodied within the social construction of teaching as a modern profession, in terms of broader aspects of social and educational change. These aspects are:

- The tension between retrospective and prospective identities

- The tension between teachers' professional status and inspection procedures

- The tension between vocation and self-interest

The article argues that these three tensions underpin contemporary education policy. It gives different examples of how this is the case in terms of teacher professionalism. Unless there is a wider awareness of how such factors influence teachers' understandings of their own professional identities, teachers will not be able to reflect on their own role within the education system, as well as within wider society. Without this necessary insight into their own status, there is a danger that teachers will simply evolve into graduate technicians rather 
than autonomous professionals in the true sense of the word, and this is likely to be harmful to education in the medium to long term.

\section{The tension between retrospective and prospective identities}

This section of the paper examines the relationship between social identity and chronological time. It defines these identities in terms of Bernstein's understanding (Bernstein, 2000). Using his definition, retrospective identities represent identities that are seen as being 'behind' time, or backward-looking. On the other hand, prospective identities are seen as being 'ahead of time', or forward-looking. This section explains why such a relationship between identity and time is vitally important to politicians, as they invoke it when formulating policies, as a means of providing a rationale that appears to go beyond the needs of the individual, locating Government policies within a wider social context instead. It also allows the exclusion of groups that do not conform to current policy initiatives or directives. This is particularly common in education reports, as seen below. However to understand fully why this has been of particular relevance to education in the late twentieth and early twenty-first centuries, it is first necessary to give some historical background.

The starting point for the contemporary age of education can probably be taken as being the 1988 Education Reform Act, brought in by the Thatcher government, and the first major education act since the Second World War. This Act has been described by Bernstein (1996) and Beck (1999) as constituting a 'rupture' in education. Educational processes that were previously considered part of a teacher's professional domain were suddenly brought into the remit of national government. Previous education acts emphasised the need for the social equality of the population at large, and education contributing towards the greater good of society as a whole. The 1988 Education Reform Act, on the other hand, was the first to introduce the concept of the market economy to education. This shift from a person-centred education system to an economy-centred system was borne out of publications such as the Black Papers, a series of pamphlets published by academics Tony Dyson and Brian Cox in the 1970s, which criticised progressive education. Similarly James Callaghan's Ruskin College speech of 1976 was also anti-progressive in tone. Another important influence was the official enquiry into the William Tynedale school in Islington, which was a primary school run as a co-operative. Eventually, these reports led to the loss of public support for the education system, alongside other developments, such as industrial action amongst teachers. In turn, this led to the imposition of centralised national education policies and procedures.

The 1988 Act brought in several key measures, aimed at transforming the effectiveness of education, via the introduction of education quasi-markets. The main measures, for the purposes of this article, were as follows:

- Inspection via OFSTED, the Office for Standards in Education

- Standard Assessment Tests (SATs)

- Grant maintained schools, directly funded by Government rather than the Local Education Authority

- National Curriculum

- League tables of test and examination results

These measures had the effect of turning the status of teachers from autonomous professionals to directed technicians, delivering a fixed canon of knowledge, in effect answerable to the Government. This was the case particularly in relation to the introduction of the National 
Curriculum and OFSTED inspections. Teachers were told what to teach, how to teach it, and how to measure the success of their teaching.

These 1988 changes were all based on an assumption that there were convergent views within society regarding expectations of pupils and teachers, and that any such expectations can only be expressed academically. It would not be appropriate to measure educational outcomes in terms of pupils' successful personal lives and their long-term career achievements years later, for example. Similarly, the curriculum could not usefully be tailored to the individual child and his or her individual talents, regardless of differing personal circumstances or varying levels of intellectual development. Knowledge was fixed in biological and chronological time - all seven year olds were required to approach their school-based learning identically, for example, regardless of whether they were learning impaired or reading GCSE science books in their spare time. This led to a dissociation of learning from the learner, as it was increasingly imposed from outside. As Bernstein (2000) argues:

Knowledge, after nearly a thousand years, is divorced from inwardness and literally dehumanised. Once knowledge is separated from inwardness, from commitments, from personal dedication, and from the deep structure of the self, then people may be moved about, substituted for each other and excluded from the market.

(Bernstein, 2000, p86)

Until now, this section of the paper has dealt with the political background to the 1988 Education Reform Act, as well as the main aspects of its content in terms of teacher professionalism. It is now necessary to link the 1988 Act with conceptions of prospective and retrospective citizens, as defined earlier. This will further illuminate the particular case of teachers, and how they are located as citizens within wider society. It will then be possible to understand the insidious effect that this has had on teacher professionalism as a whole.

Through the introduction of the 1988 Education Reform Act, we have seen that the Government sought to remedy the perceived problems in education by controlling the content and processes of education, leading to a standardised, impersonal product. This led to a shift in the nature of the pupil-teacher relationship, with teachers being increasingly perceived as deliverers of this product, rather than true partners in an educational sense. To justify this fundamental shift in the nature of teacher professionalism itself, Governments have repeatedly invoked a rhetoric of rapid social change. In post-industrial society, citizens are required to be endlessly flexible, repeatedly reinventing themselves to conform to changes in the society around them. A good example of this type of thinking can be found in the Dearing report entitled Higher Education in the Learning Society (NCIHE, 1997).

To survive in the labour market of the future, workers will need new sets of skills, to work across conventional boundaries and see connections between processes, functions and disciplines and, in particular, to manage the learning which will support their careers. (NCIHE, 1997, pp 56-57)

This is what Bernstein termed the 'prospective', forward-thinking citizen, who needs to retrain continually, at their own expense and in his or her own time. If citizens fail to do this, they run the risk of being pathologised by Government. They can be perceived as backward thinking and authors of their own misfortune, or what Bernstein would call a 'retrospective' citizen. Tight (1998) argues, for example, that this type of thinking can be found in a range of Government reports to do with education, and that individuals are positioned according to 
how far they conform to the ideology of lifelong learning being necessary. Therefore teachers are caught in a political double bind. They have to believe in the ideology of lifelong learning, as this justifies their existence as educators. At the same time, they are required to be endlessly flexible in terms of their professional skills, which may mean adopting different skills and viewpoints in relation to education at any point. Essentially, therefore, this runs the risk of having a destabilising effect on teacher professionalism as a whole.

This destabilisation is symptomatic of the main problem in defining contemporary teacher professionalism: how do teachers reconcile the personal and professional, in addressing current education policies during the course of their work and careers? Other researchers have identified different models that seek to address this problem. To give two examples, Goodson and Hargreaves (1996) refer to models such as 'classical professionalism' which takes medicine and law as an example, in which teachers rely on a body of knowledge closed to outsiders. Whitty (2002), on the other hand, puts forward the idea of 'democratic professionalism', in which teachers build partnerships with other stakeholders in the education process. These models may offer a solution to the question of reconciling the personal and professional in teacher professionalism, but further debate is vital within the educational community, if there is to be sufficient ownership of such models by teaching professionals.

\section{The tension between teachers' professional status and inspection procedures}

In the section above, there was brief reference to the changes that came about as a result of the 1988 Education Act in relation to inspection procedures. This section will consider these changes in more depth, and link them to the apparent deprofessionalisation of the teaching profession, using generic examples from other private and public sector professions to illuminate such changes. This will start with an analysis of what defines professionalism in sociological terms.

The sociologist Talcott Parsons has been described as one of the first sociologists to identify professionals as a distinct sociological group. Historically the original professions were considered to be medicine, law, the clergy and university teaching. Now many other occupations also regard themselves as being professional. These occupations might include accountancy, nursing, social work, school teaching, and similar groups. It could be argued that the term has been overused in contemporary society. It is even possible to describe someone as a 'professional' customer service officer, pest control officer or plumber, for example, suggesting a certain degree of competency and ethical practice.

As a result of this expansion in the number of occupational groups, there has been ongoing academic debate about what characterises a true profession. Throughout the literature, the main characteristics of a profession tend to be listed as follows (although this list is not exhaustive): 
- Exclusive body of knowledge, determined by members of the profession, and closed to outsiders

- Ability to determine own fee

- Autonomy in relation to working practices

- Self-regulation by members of the profession

- Promotion of members' interests within society

- Inherent guarantee of integrity, standards and ethical practice through the use of a moral code

- Altruism

In the case of teachers, we can see some anomalies within this list, suggesting that teaching is not necessarily a profession in the traditional sense of the word. Teachers are usually subject to a national pay agreement, or pay scale of some kind, which suggests that they are not at liberty to set their own fees. They work in relatively large, complex organisations, and their activities are tightly controlled through the use of a set curriculum as well as timetables, year plans and institutional structures which may be imposed from above. There is an element of self-regulation, in the form of disciplinary procedures undertaken by the General Teaching Council, but this is overridden by school inspection procedures carried out by OFSTED. The teaching unions play an important part in promoting members' interests, but this does not always inspire the confidence of the public, as could be seen in the public response to industrial action in the late 1980s and early 1990s. Teachers may feel that some of the educational practices demanded of them may be unethical, such as being prohibited from providing simple elements of personal care to children under five, for example, or being obliged to submit children to Standard Assessment Testing when this may be untimely or unsuitable for the children concerned. However they are not at liberty to discard these demands and apply their own professional moral code to particular situations. In short, the working lives of teachers are so tightly controlled it is unclear whether their profession is a true one in the sense of the term defined above. It could be argued that it is what Etzioni (1969) would term a 'semi-profession'. In other words, while teachers' professional lives may demonstrate many of the characteristics of professionalism, the tightly controlled, complex environments in which they operate preclude true professional status.

This difference in status is important for understanding the effect that the 1988 Education Act had on teacher professionalism, both in terms of self-regulation and in terms of standards of professional practice. Before 1988, there had been inspection at a local level via Local Education Authorities (LEAs), overseen by Her Majesty's Inspectorate (HMI). This encouraged collaboration between inspectors and teachers, aimed at helping teachers to improve their professional practice. The introduction of OFSTED meant something quite different, as schools and teachers were scrutinised in considerably more detail, with little right of reply. Subsequently many teachers considered themselves to be under a great degree of personal stress during OFSTED inspections. A good example of the social construction of emotions in these circumstances can be found in Jeffrey and Woods (1996), which illuminates and theorises numerous tensions between the personal and the professional for teachers during school inspections. This theorisation has strands in common with one of Nias's models of teacher professionalism, namely 'Career as Identity' (Nias, 1981). If Nias's model is valid, in that many teachers identify closely with their professional roles, it is understandable that teachers take school inspections personally. This will be discussed in more detail in the next section. 
Relating to their professional role is clearly important for teachers, and therefore it seems strange that inspection processes were developed by Government that failed to take into account this important characteristic of teachers' identities. One explanation for this is the desire on the part of Government to introduce managerialist techniques to education, as a way of reforming the sector, which was seen as underperforming, as discussed previously in this paper. There is no distinct definition of the term 'managerialism' in the academic literature, but it touches on the following aspects of contemporary management:

Managers become a distinct occupational group, and have a clear right to manage. This is in contrast to a primer inter pares model that implies the manager is a professional peer who happens to occupy a position of leadership.

There exists a client group which demands accountability and responsiveness. Therefore services should be grounded in the needs of the user.

All parties have an equal status in terms of power relationships, and are to be regarded as stakeholders.

If we consider these characteristics in terms of teacher status and school inspection, we can see that the introduction of managerialism in education had a negative effect on the relationship between teachers, and the external environment in which they operated. Taking the first bullet point, teachers were perceived as requiring increasing amounts of management. Indeed 'directed time' was introduced by the 1988 Act as a means of allowing head teachers (and indirectly Government) to define increasingly tightly the tasks required of teachers, and the location of those tasks. This had the effect of undermining teachers' professional autonomy, as they were no longer able to decide how they should work to best effect. The second point suggests that teachers are service providers, and that they should be accountable to the recipients of the services they deliver, as opposed to being accountable to society at large in a medium to long-term sense. Teachers were thereby rendered governable, rather than self-regulating as a profession. This was achieved in Governmental terms through the introduction of a national system of pupil testing and school inspection, based on a rigid conception of what constituted a good education. Teachers were not at liberty to adapt this framework to accommodate the individual needs of their pupils without Government authorisation, even if their pupils had severe learning disabilities, for example. Finally, the status of teachers was undermined by the equality of non-teachers in power relationships. Teachers could no longer claim privileged access to a closed body of knowledge, which is possibly the main characteristic of a true profession. An example of this was that lay members were included in inspection teams, and were allowed to pass judgement on teachers.

In the first main section of this paper, it was argued that shifts in the social location of identity destabilised teacher professionalism after the 1988 Act. This was because teachers were obliged to conform to a Government model for education, for fear of appearing 'backward looking' or behind time, which was termed having a 'retrospective identity' by Bernstein (2000). Similarly the introduction of an inflexible system of school inspection by Government had a negative effect on teacher status, for the reasons outlined in this section. Therefore it is clear that fundamental changes were taking place within teaching as a consequence of Government policy. The third and final section will examine the tension between ideas of vocation amongst teachers, and the requirement that teachers act increasingly as education technicians, delivering policy-based education determined by Government. 


\section{The tension between vocation and self-interest}

In the introduction to this paper, there was a description of Teacher Barbie, which gave an example of a teacher stereotype in popular culture. Similarly embedded within a traditional view of the teacher is the idea that there is an underlying sense of vocation. This can certainly be seen in the work of Nias (1981, 1987, 1996 and 1997). In her analysis of teacher identity amongst primary school teachers, she examined how teachers perceived themselves, and how they were viewed by society. Her findings suggested that these teachers identified very closely with their professional roles, which is something touched on earlier in this article. This can be classified sociologically as habitus, which is a term used by Bourdieu (1977) and others. The term suggests the adoption of a total personality type that represents all it means to be a teacher. It is achieved over the course of a period of apprenticeship, with changes taking place gradually. In this sense, it is something of a metamorphosis. He describes how a professional persona develops over time, and draws parallels with the sanctification of the priesthood. There are indeed comparisons that can be made in this respect, such as qualifications for entry (in this case, graduate status) ongoing training (for example Initial Teacher Training followed by Continuing Professional Development), and the adoption of a state of grace (in the case of teaching, Qualified Teacher Status, although admittedly this is not generally seen as a religious phenomenon).

If teachers are expected to have a vocation through a sense of habitus, it suggests a degree of internal regulation and ethical control. This was listed in the first section of this paper as a characteristic of professionalism. However the Government initiatives put in place after the 1988 Act rely on external regulation. Bernstein (2000) and Beck (1999) argue that this is embodied in Government policy. By analysing some of the key characteristics of the post1988 education landscape, several examples of external regulation become apparent.

The introduction of the National Curriculum meant that no prior assumptions were made regarding the inner state of the teacher, and that they needed to be told what and how to teach. This is in contrast to the previous situation, which implied that teachers were able to develop and deliver curricula in their own right.

Teachers were regarded as infinitely and adaptable to circumstance. This was discussed in relation to lifelong learning and retraining earlier in the paper. Bernstein and Beck both argue that this is in contrast to teachers developing a total personality type that is a teacher. There was the use of state agency for regulation, which is manifested by OFSTED as a qualitariat. This suggests that teachers are unable to provide guarantees of professional integrity through the use of a moral code, and need to be supervised by Government.

We can see that as a result of the 1988 Act, there was a significant change in the nature of the discourse surrounding education. This means that teachers' lives became more policy-driven and less vocation-driven, as the Government sought to impose an idealised version of teacher identity on the profession. Ideals such as altruism and public service were simply not promoted within this model. Instead, there was an emphasis on short-term results, such as GCSE league tables. This shift in emphasis encouraged teachers to be more opportunistic, and such a model of professionalism was described by Nias as 'Commitment as Career Continuance'. This is a more self-interested model of teacher behaviour (Nias, 1981). Nias defines it as a desire to build a career, perhaps to support dependants. This is in contrast to Nias's models of 'Commitment as Caring', which assumes a vocational element to teaching, or 'Commitment as Identity', which involves identification with what it means to be a teacher, or habitus. 
Perhaps this final tension implies that teaching in is a state of transition. The new ideal type of teacher is able to behave in a flexible way, responding to Government policy as necessary. There is a degree of self-interest for teachers in doing so. Implicit within this is a tacit invoking of the invisible hand by the profession - in other words, by doing what is best for themselves (i.e. conforming to Government policy for education), teachers are doing what is best for society at large. Such an approach to teaching certainly leads to more consistent provision of education services. However there is a problem. Should Government policies prove to be flawed at any point, teachers will be unqualified to identify and remedy the errors, as they will have become deskilled as a consequence of their training and professional practice. If this is ever the case, then teachers will have become little more than technicians.

\section{Conclusion}

This article examined the contemporary status of teachers in relation to Government policy and the post-industrial knowledge economy. It examined in detail three tensions that are evident within this relationship.

- The tension between retrospective and prospective identities

- The tension between teachers' professional status and inspection procedures

- The tension between vocation and self-interest

The article argued that teachers' professional identities were located in time, and that this was exploited by Governments seeking to invoke a rhetoric of rapid change. If teachers objected to changes in education policy, they ran the risk of being labelled backward-looking and out of touch. If they failed to conform to the frameworks for education laid down in law, they ran the risk of being labelled incompetent. Finally, if they sought to involve a real sense of vocation in their work, they ran the risk of being labelled irrelevant, if their views failed to align with those of Government. The consequence of this was that teachers were effectively being controlled and deskilled, and the article argued that the profession was in a state of transition as a result.

These three tensions highlight a real risk that, for the time being at least, education will increasingly deal only with the most visible aspects of human achievement, This can be seen in the current emphasis on examination results and education's contribution to the national economic growth, for example, at the expense of more substantial aims, such as creating a happy and balanced society. Following the intellectual structure of the arguments contained within the article, I would like to suggest that there is a further tension represented within current education policy, which is evident in each of the three strands of debate above. As discussed earlier in this article, Whitty (2002) promotes a democratic model of teacher professionalism, in which teachers express their integrity through collaborative work with other stakeholders in education. This would certainly be a positive resolution to the current transition in teacher professionalism. My own view of the future tends towards the more dystopian. I believe we have to develop a shared set of values for education which transcends politics. However, as a result of the politicially-motivated 1988 Education Reform Act, we have some distance to go before achieving this. In the face of these relentless political pressures, those of us who care about the future of society must continue to promote education in terms other than what it contributes to the national economy. I look forward to a more insightful Education Act around 2020, when we start to work collectively and democratically towards improving the sum total of human happiness. I hope that is what it will mean to be a teacher in the future. 
The author would like to thank John Beck, Robert Moore, Mike Baker and Geoff Whitty for their help in debating the arguments contained within this article. The article is adapted from her book Teachers Under Siege (2006).

\section{References}

Beck, J (1999) "Makeover or Takeover? The strange death of educational autonomy in neoliberal England" in British Journal of Sociology of Education (Vol 20 No 2, June 1999) pp 223-238

Beck, J (2002) "The Sacred and the Profane in Recent Struggles to Promote Official

Pedagogic Identities" in British Journal of Sociology of Education Vol 23 No 4, Dec 2002 pp 617-626

Bernstein, B (1996/2000) Pedagogy, Symbolic Control and Identity: Theory, Research, Critique (London, Taylor and Francis)

Etzioni, A (Ed) (1969) The Semi-Professions and their Organization (New York, Free Press) Goodson, I and Hargreaves, A (Eds) (1996) Teachers' Professional Lives (London, Falmer Press)

Jeffrey, B and Woods, P (1996) "Feeling Deprofessionalised: the social construction of emotions during an Ofsted inspection" in Cambridge Journal of Education, Vol 26 No 3 Leaton Gray, S (2006) Teachers Under Siege (Trentham Books)

NCIHE (1997) Higher Education in the Learning Society (London, HMSO) [The Dearing Report]

Nias, J (1981) 'Commitment and Motivation in Primary School Teachers' in Sociology Vol 37 No 3 Aug 2003 pp 433-457

Nias, J (1987) Seeing anew: teachers' theories of action (Victoria, Deakin University Press) Nias, J (1989) Primary Teachers Talking: A Study of Teaching as Work (London, Routledge) Nias, J (1996) "Thinking about Feeling: the emotions in teaching" in Cambridge Journal of Education Vol 26 No 3 pp 293-306

Tight, M (1998) "Education, education, education! The vision of lifelong learning in the Kennedy, Dearing and Fryer Reports" in Oxford Review of Education, Vol 24 No 4, Dec 98, pp 473-485

Whitty, G (2002) Making Sense of Education Policy (London, Paul Chapman) 